\title{
Categorization and Features of Simplification Methods in Visual Design
}

\author{
Chun-Cheng Hsu1, Wei-Yao Wang² \\ ${ }^{1}$ Institute of Applied Arts, Industrial Design Group, National Chiao Tung University, Taiwan \\ ${ }^{2}$ Department of Design, National Taiwan University of Science and Technology, Taiwan \\ Email: chuncheng@mail.nctu.edu.tw
}

How to cite this paper: Hsu, C.-C., \& Wang, W.-Y. (2018). Categorization and Features of Simplification Methods in Visual Design. Art and Design Review, 6, 12-28.

https://doi.org/10.4236/adr.2018.61002

Received: November 25, 2017

Accepted: February 4, 2018

Published: February 7, 2018

Copyright (c) 2018 by authors and Scientific Research Publishing Inc. This work is licensed under the Creative Commons Attribution International License (CC BY 4.0).

http://creativecommons.org/licenses/by/4.0/

(c) (i) Open Access

\begin{abstract}
Simplification is a very important graphic design method used by designers to make graphics more memorable and immediately recognizable, and is utilized in logos, symbols, posters, computer icons, and other design applications. The purpose of this study is to investigate the categories and features of simplification in graphic design. A review of relevant literature and a focus group technique are the main methods used in this research. The conclusion revealed that graphic simplification modes may be divided into extraction of the complete form and extraction of partial features. The former can be further divided into 1) rendering external outlines, 2) preserving structural relationships, 3) flattening, and 4) simplifying geometry. The latter can be divided into 1) emphasizing visual features, 2) emphasizing functional features, and 3) preserving surface patterns. This study also discusses and compares the features of these methods as used in design teaching and practical design.
\end{abstract}

\section{Keywords}

Categorization of Simplification Methods, Visual Design, Design Method

\section{Introduction}

When designers render a "subject", they usually "simplify" its original outline, allowing the viewers to easily understand its uniqueness or to make it memorable (Gombrich, 1982; Kress \& Van Leeuwen, 1996; Wang \& Hsu, 2007). Taking the animated movie "The Incredible" visual settings for example (Figure 1), designers use simple geometric shapes and lines to form a unique style of characters and scenes. Nowadays, AR and VR media rely heavily on visual design such as figures, objects and scenes; the design of $2 \mathrm{D}$ or $3 \mathrm{D}$ images is all very important. Bell (1913) believed it is necessary to use simplification to extract interesting 


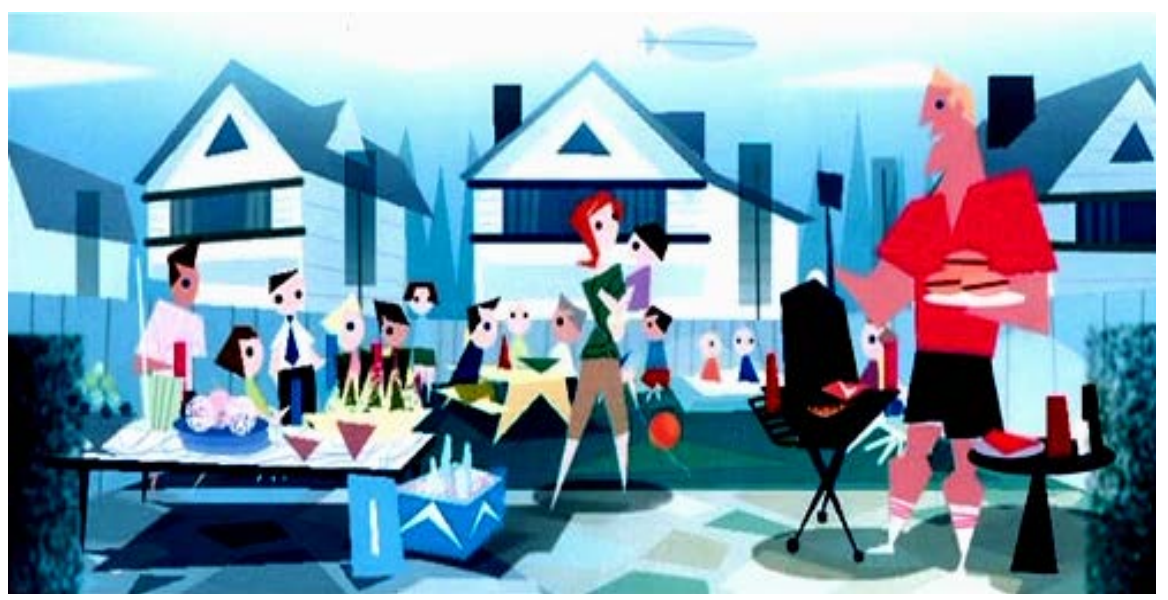

Figure 1. 2D visual style of film "The Incredible” (Source: Disney).

aspects from an uninteresting subject. He admired artists like Cezanne, who were skilled in the use of simplification. In Cezanne's work, "The Card Players" (Figure 2), he made use of human poses and facial expressions to show the moods of gamblers and the tense atmosphere of the gambling den. Figure 3 shows a simplification experiment conducted by Doesburg on Cezanne's work, simplifying the elements of the original into geometric shapes. Furthermore, he used the geometric form to reinforce the tension of the standoff between the three parties. Doesburg's second simplified work, "The Card Players" (Figure 4), totally abandons the limitations of the original structure of the image; the artist is able to highlight the concentration and tense expressions dominating the gambling table by using irregularly sized matrices, overlapping and distorting the proportion. In Figure 4, one can also see the cues that Doesburg utilized to preserve the structure of the original painting: arms, fingers holding cards, and the chairs.

The Gestalt School was one of the pioneers in systematically carrying out research in this area. They proposed a Principle of Simplicity, known as the Law of Pragnanz, meaning that the Good Form is one that has undergone appropriate "simplification", since man's visual cognition leans more towards using the most economical means of receiving messages (Arnheim, 1974; Koffka, 1935). Although the Gestalt School identified many different examples of visual simplification, they did not have an effective way to define what kind of shape should be considered the simplest or "the best". Their judgment was very subjective (Eysenck, 1998; Eysenck \& Keane, 2005; Goldstein, 2002).

The abstraction uses a strategy of simplification to simplify the shape of the original object to enhance the recognition or impression of viewers (Arnheim, 1969; Gombrich, 1982; Hsu \& Wang, 2010).

The simplification principle is often used in designing signs or computer icons (Figure 5). There are many academic studies on this subject. For example, Meyer \& Laveson (Meyer \& Laveson, 1981) explored graphic simplification from the viewpoint of ergonomics, classifying it into five simplification levels, from actual 


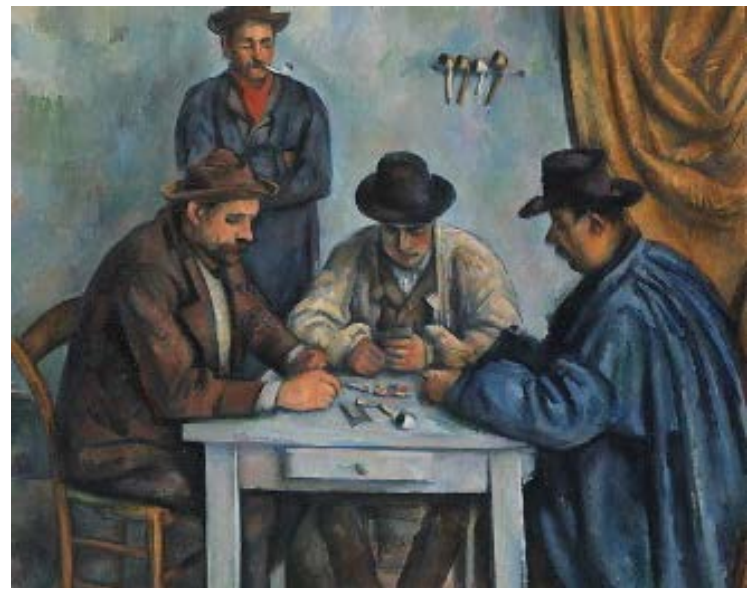

Figure 2. Cezanne’s Cardplayers, 1892.

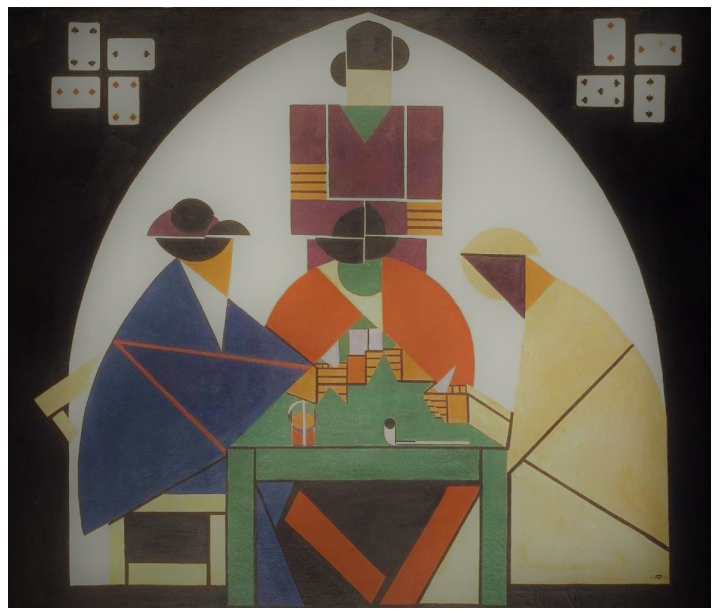

Figure 3. Doesburg's Cardplayers, 1916-17.

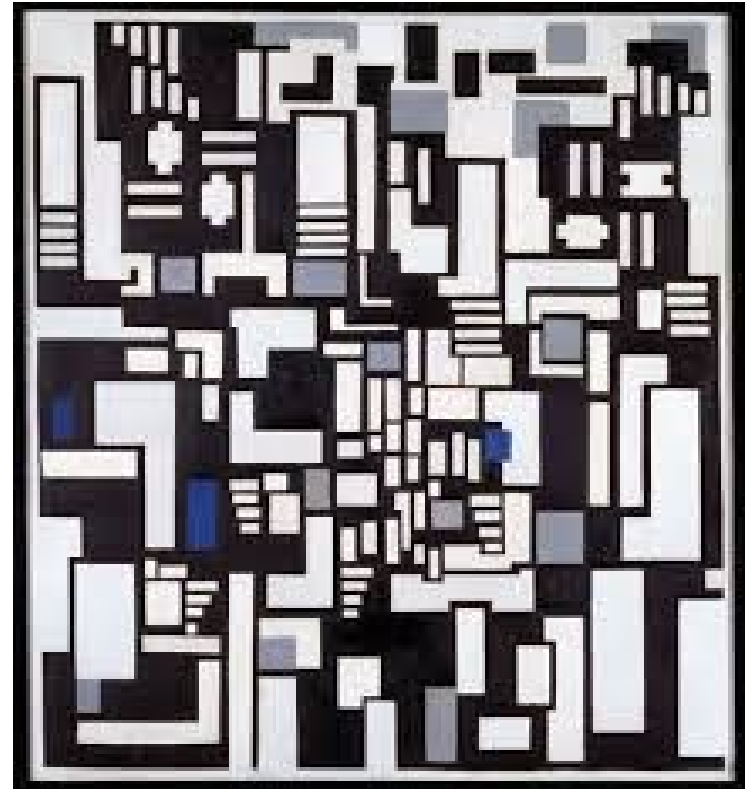

Figure 4. Doesburg's Cardplayers, 1917. 
object to abstraction: 1) Natural Photography, 2) Pictorial Illustration, 3) Graphic Rendering, 4) Graphic Symbology, and 5) Abstract Symbology (Figure 6). Lin (1992) presented three major methods of transforming actual objects into graphics, each preserving a feature of the original: 1) shape feature, 2) image feature, and 3) function feature (Figure 7).
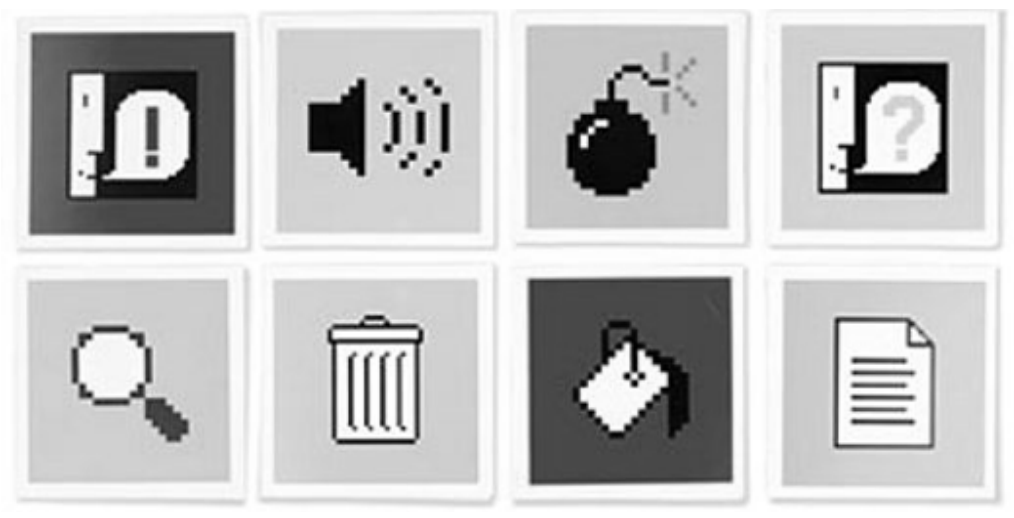

Figure 5. Computer icons.
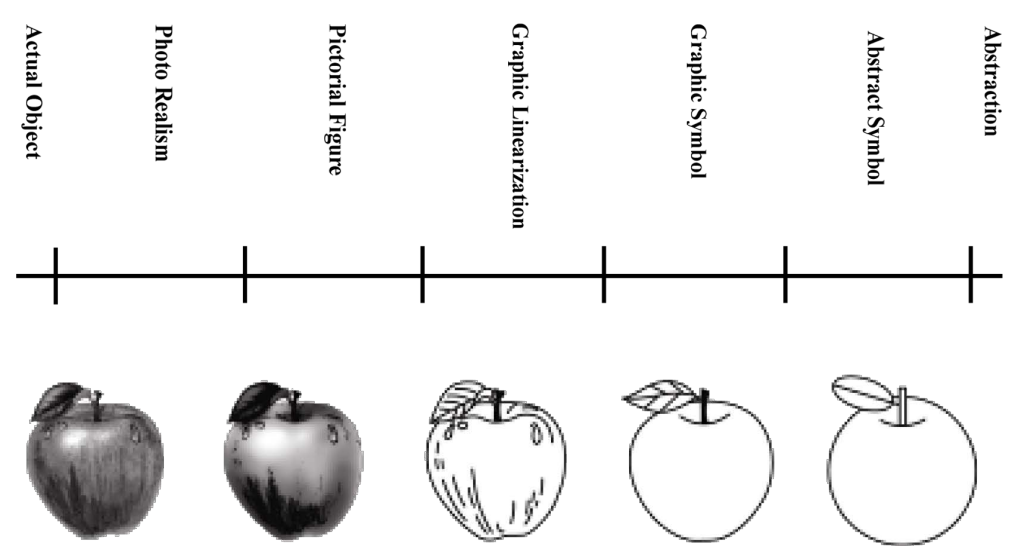

Figure 6. Five processes of graphic simplification.

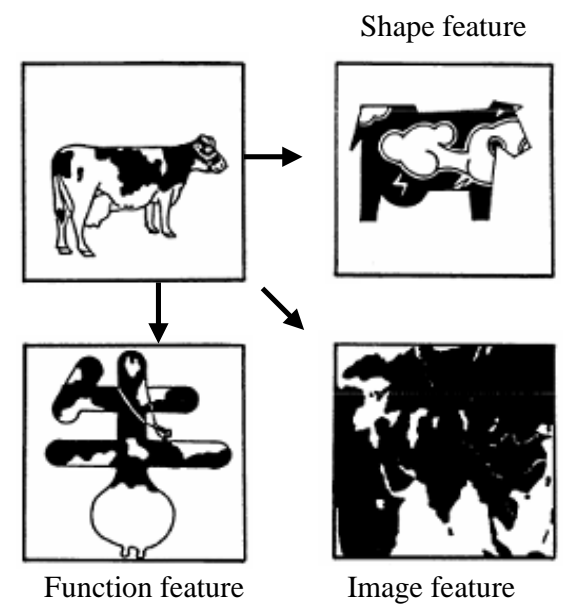

Figure 7. Three major methods of transforming actual objects into graphics, while preserving certain original feature (Lin, 1994). 


\subsection{The Application of Simplification Methods in Art and Design}

The purposes of simplification in the visual arts and design are different. In the visual arts, simplification may be used by artists to express their creativity and experimentation, while in the design field, simplification may be used as a means to relay messages which are more accurate and easier to remember (Gombrich, 1982; Hsu \& Wang, 2010). Thus the designer must consider the viewer's ability to recognize an image (Wang \& Hsu, 2007).

\subsection{The Use of Simplification in the Visual Arts}

At the peak of the abstract art movement, many art works with simplified subjects were produced. Below are two works used to explain the use of simplification: 1) Doesburg's simplified experimental work, "Cow" (Figure 8), and 2) Lichtenstein's “Cow Going Abstract” series (Figure 9).

Doesburg's "Cow" series (Figure 8) simplifies the cow image by eliminating details one at a time, transforming the actual object into geometric shapes in four stages.

Lichtenstein's "Cow Going Abstract” (Figure 9) simplifies the cow image in three stages. He abandons the limits of the actual subject, carrying out a breakdown and reorganization of elements. When simplification reaches the third stage, the painting becomes dependent on only several straight lines and simple colours to preserve the cow's features.

\subsection{The Use of Simplification in Design}

In comparison with simplification in the visual arts, used for creative interpretive purposes, simplification in the field of design serves practical purposes. Design prioritizes the efficient, accurate transmission of these simplified graphics to the viewers (Hsu \& Wang, 2005).
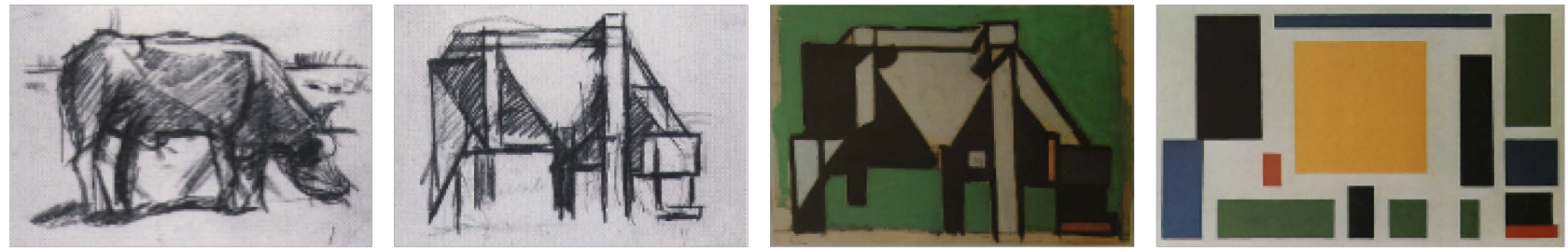

Figure 8. Doesburg's “Cow' series” (1917).
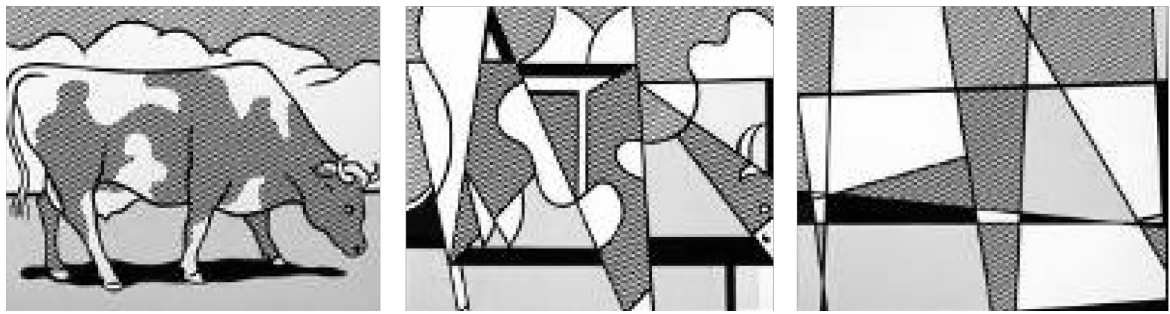

Figure 9. Lichtenstein's “Cow Going Abstract” (1982). 
This design simplification method is frequently used in poster design. For example, Japanese designer Tanak Ikko simplifies the head of a traditional woman, preserving only a few features that can be used to create stylistic graphics (Figure 10). The poster (Figure 11) and logo (Figure 12), created by American designer Saul Bass, also make good use of simplified lines and forms.

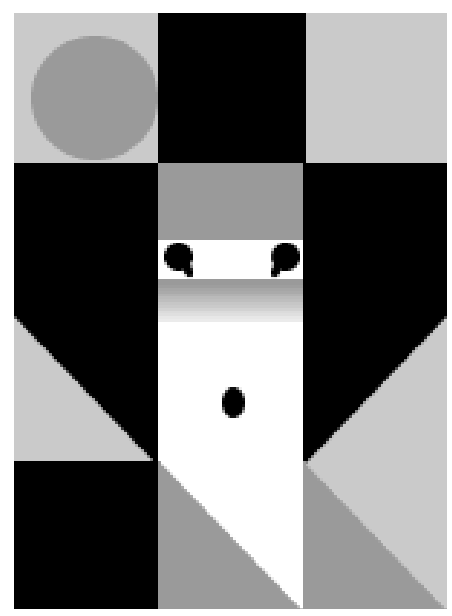

Figure 10. Poster design by Tanaka Ikko (1981).

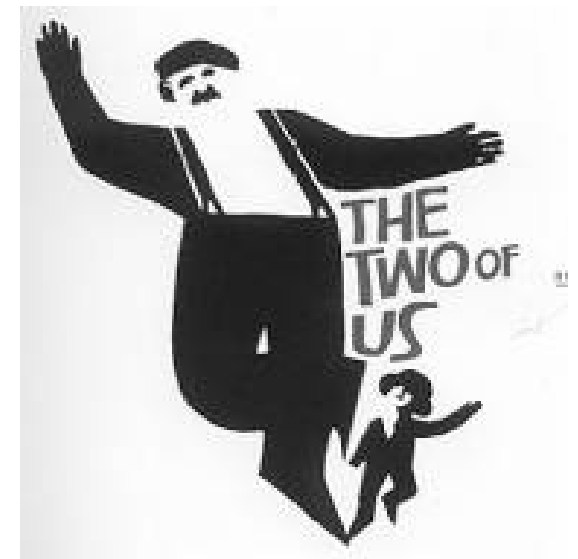

Figure 11. Saul Bass' poster for the film, “The Two of Us” (1968).

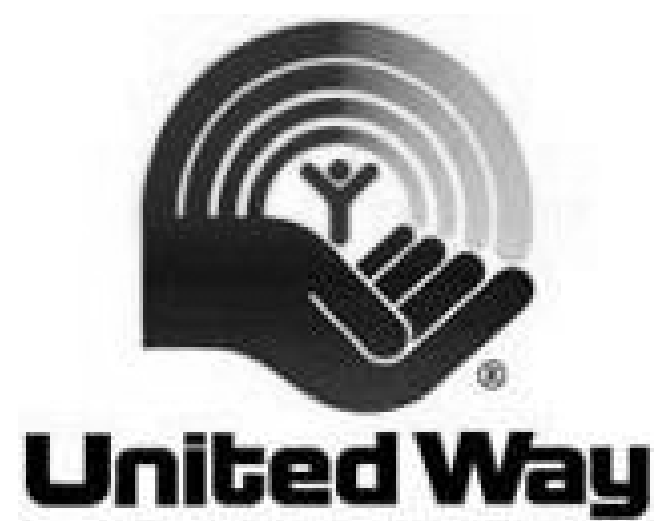

Figure 12. Saul Bass' logo design for United Way charity (1972). 


\section{Purposes and Process of the Research}

This study focused on the graphic simplification in the design field. According to Merriam-Webster dictionary, the definition of "graphic" is the art or science of drawing a representation of an object on a two-dimensional surface, and the way a designer renders an object is primarily related to the simplification of details and preservation of special features (Arnheim, 1969; Gombrich, 1982). However, earlier studies focused mainly on the theories of visual psychology; not many of them looked into the design principles and process itself. Consequently, this study hopes to delve deeper into graphic simplification methods, to be able to benefit the actual design process by using rational analysis to discuss instinctive design behavior. The purpose of this study is to analyze different methods of simplification used in graphic design.

A review of relevant literature and a focus group technique are the main methods used in this research. The research process was divided into two stages: The first stage involved the selection of graphic examples from websites and books on art and graphic design history, including: "A Century of Graphic Design” (Aynsley, 2001), "Six Chapters in Design" (Meggs, 1997), "A Concise History of Modern Painting" (Read, 1985), "Pop Art" (Lippard, 1985), and "Picasso. Picasso" (Hsiung Shih Arts, 1976), each book was provided by experts participating in this research. The researcher filtered the samples subjectively in advanced.

In the second stage, this study used the focus group technique. The focus group is a kind of group interview where people share ideas and provide rich qualitative data (Krueger \& Casey, 2000). This study used a small group consisting of eight graphic designers, each with more than six years of professional experience, discussing, categorizing, and analyzing the operational modes and methods of various forms of design simplification.

The group openly discussed the features of each simplification method. First the research topic was explained to the participants, and then it was decided that cows would be used as the subject for sample images. It is generally easier to use a single subject for comparison, and the cow is commonly used in many simplified art and graphic design works. 316 graphics were chosen to discuss and were printed into 316 cards. 316 cards were spread out on the table, and eight experts discussed and sorted out the cards using three stages of KJ method. Once the cards have been sorted into groups, the experts may sort large clusters into subgroups for easier analysis. In each stage of grouping, if more than half of the experts didn't agree, it was necessary to discuss until they found the consensus.

\section{Categories and Features of Simplification Methods}

Through discussions among the eight experts by using KJ method, the study made the following discoveries based on Hsu \& Wang (2010)'s research. Methods of simplification used in graphic design may be divided into two modes: extraction of the complete form and extraction of partial features. The former can be 
further divided into 1) rendering external outlines, 2) preserving structural relationships, 3) flattening, and 4) simplifying geometry. The latter can be divided into 1) emphasizing visual features, 2) emphasizing functional features, and 3) preserving surface patterns. Detailed explanations are as follows:

\subsection{Two Modes of Graphic Simplification}

The study was able to identify two major modes of graphic simplification: extraction of the complete form and extraction of partial features.

\subsubsection{Extraction of the Complete Form}

This simplification method preserves the relationship of the subject's complete structure and the corresponding positions of its constituent parts. Figure 13 shows that a combination of simplified forms may also be substituted for more complex parts and detailed human forms. This mode of simplification is suitable for objects at the basic level of categorization (Rosch, Mervis, Gray, Johnson, \& Boyes-Braem, 1976), such as dogs, cows, and even people, whose silhouettes are easily distinguishable from each other. Nevertheless, at levels of categorization subordinate to this, the silhouettes of object become very similar, which makes this method of simplification inappropriate. For example, it is impossible to identify who the man is from the simplified image representing a man.

\subsubsection{Extraction of Partial Features}

This simplification method focuses on the preservation of one or more of the major parts or elements of the subject (Wang \& Hsu, 2007). As shown in Figure 14, on the left is Charlie Chaplin's full image, containing the hat and moustache, which are major elements that uniquely represent Charlie Chaplin. Compared to these icons, the body is a secondary element. The image on the right is the form produced by extraction. Although most of the elements identified with the original person have been omitted, it is still possible to identify the simplified graphic as Charlie Chaplin, because the key elements have been preserved. In comparison

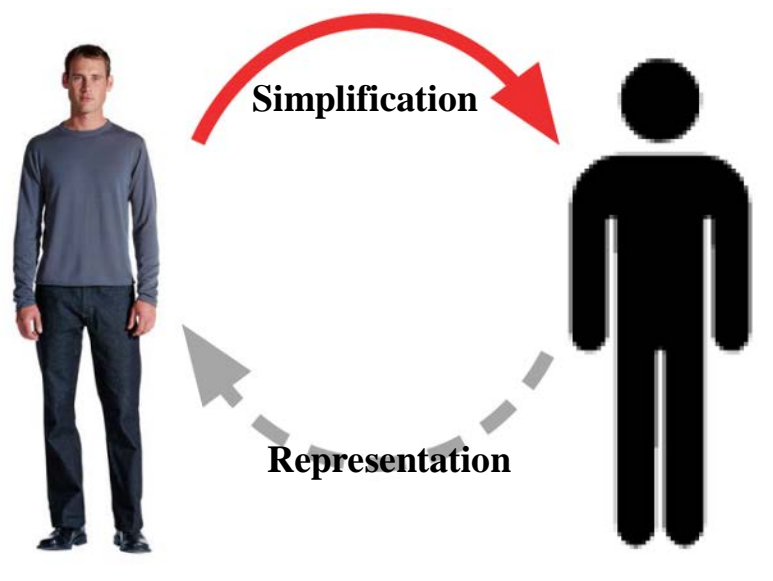

Original object

Form after

Figure 13. Extraction of complete form (from Hsu \& Wang, 2010). 


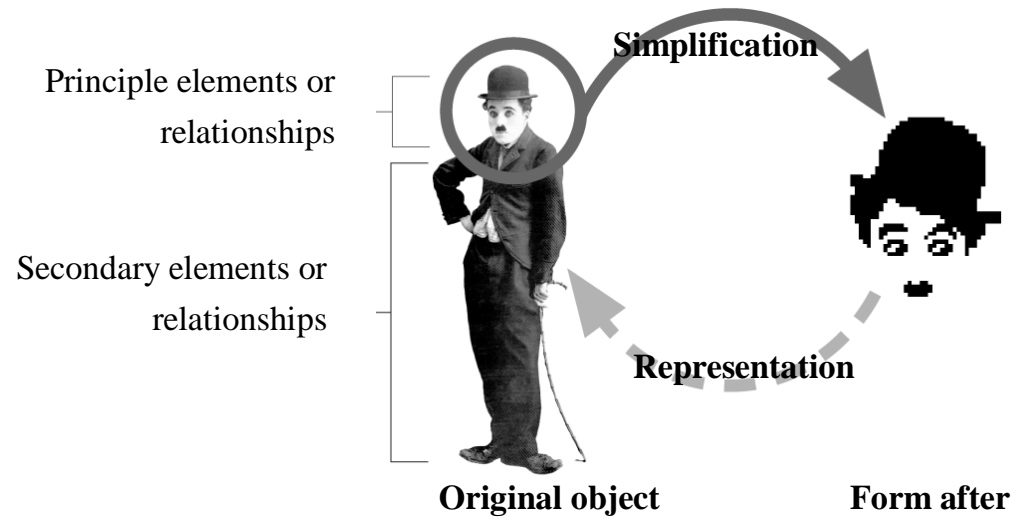

Figure 14. Extraction of partial features (from Hsu \& Wang, 2010).

with the "extraction of the complete form", this method is better able to present the subject in greater detail; it is not only possible to identify the graphic as a man, but also, which man. However, in this method we are faced with the difficult task of selecting which major features we are going to use; there are no objective criteria by which the designer can base his judgment of what constitutes an important feature. The selection involves both the personal experience of the designer as well as cognitive issues.

\subsection{Methods of Graphic Simplification}

Based on the two major modes of simplification, this study goes a step further, using the cow as an example to specifically demonstrate the seven methods of graphic simplification.

\subsubsection{Extraction of the Complete Form}

1) Rendering external outlines

In the "rendering external outlines" method, all one has to do is to directly render an outline of the subject. This design process can be made more convenient with the help of layering and tracing functions in design software. The internal texture, lines, and detailed structure of the subject may be omitted when it is being drawn, and the external form may be delineated through closed outlines. The advantage of this method is that it preserves the features of the subject's external outline, and also omits detailed or complicated internal elements (Figure $15)$.

The most effective way to make use of this method is to select the angle from which the object is often seen. As can be seen in silhouettes of the cow viewed from four different angles (Figure 16), the far left image is the most easily recognizable, because it is the angle that people are most familiar with (Palmer, Rosch, \& Chase, 1981). However, the method is not suitable for objects with very similar or non-unique shapes, such as soccer ball and oranges (Figure 17(a)), or digital cameras and air-conditioners (Figure 17(b)). The silhouettes of these objects are difficult to distinguish. 

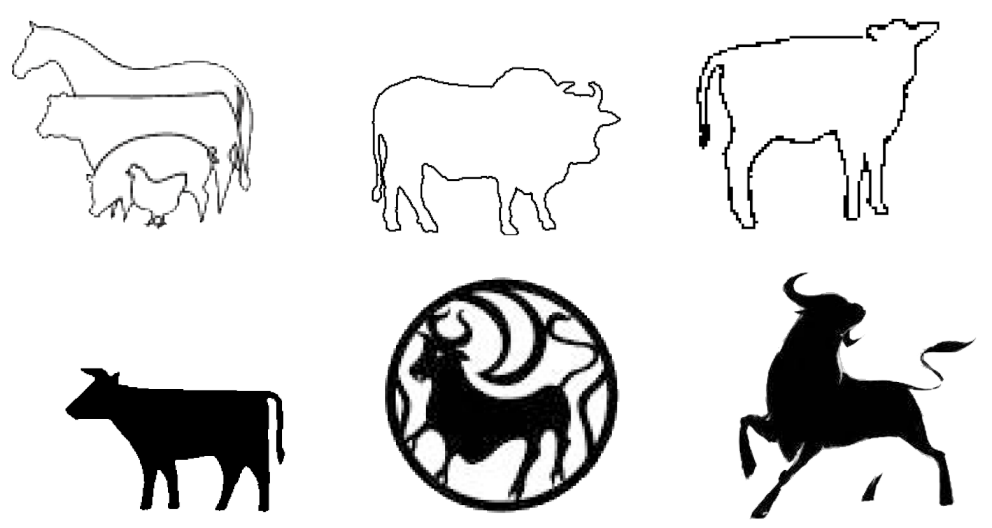

Figure 15. Simplification method of outline rendering.

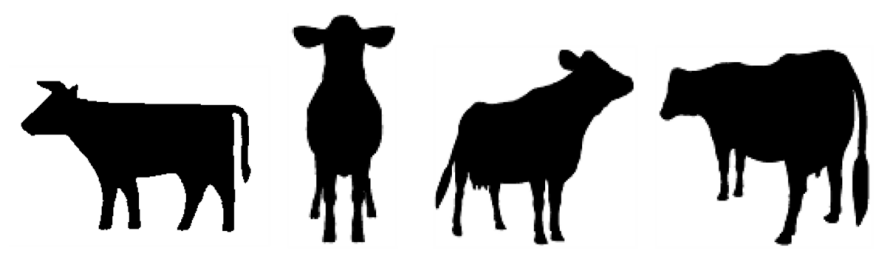

Figure 16. Silhouettes of the cow, viewed from four different angles.

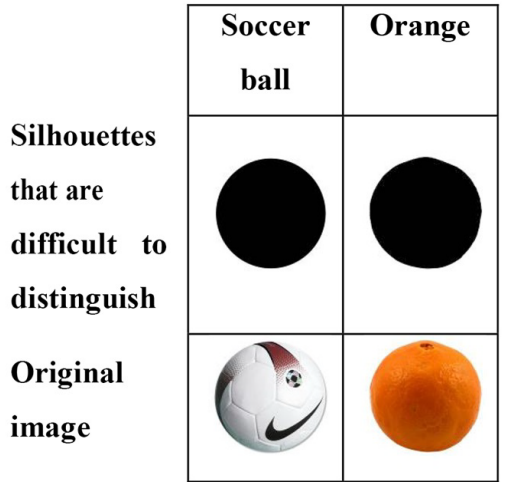

(a)

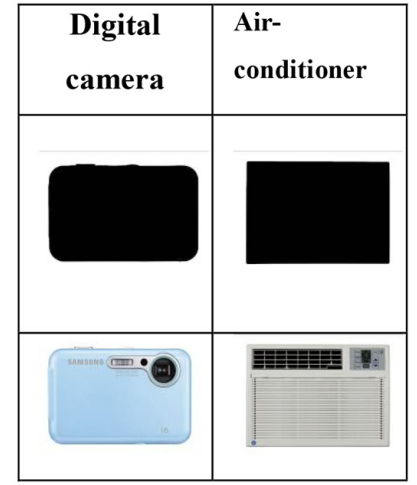

(b)

Figure 17. (a) Spherical objects; (b) Rectangular objects.

\section{2) Method two: Preserving structural relationships}

In contrast with rendering external outlines, simplification while preserving structural relationships emphasizes the corresponding relationships and proportions of the subject's structure: for example, in substituting basic geometric forms for individual parts of the subject and retaining their corresponding relationships, proportions, and positions (Figure 18). The advantage of this method is that it is easier to create diverse visual styles. However, the disadvantage is that if you over-simplify, it is difficult to discern adequate information to identify the subject (Figure 19).

\section{3) Method three: Flattening}

This method omits lines, textures, and other attributes of the subject that create an impression of three-dimensionality. It uses only the simplest lines and 
colours to present more important features of the subject, displaying a unique visual style which is often used in graphic design and illustration applications (Figure 20). However, ensuring that the design, selection of hues, layering of

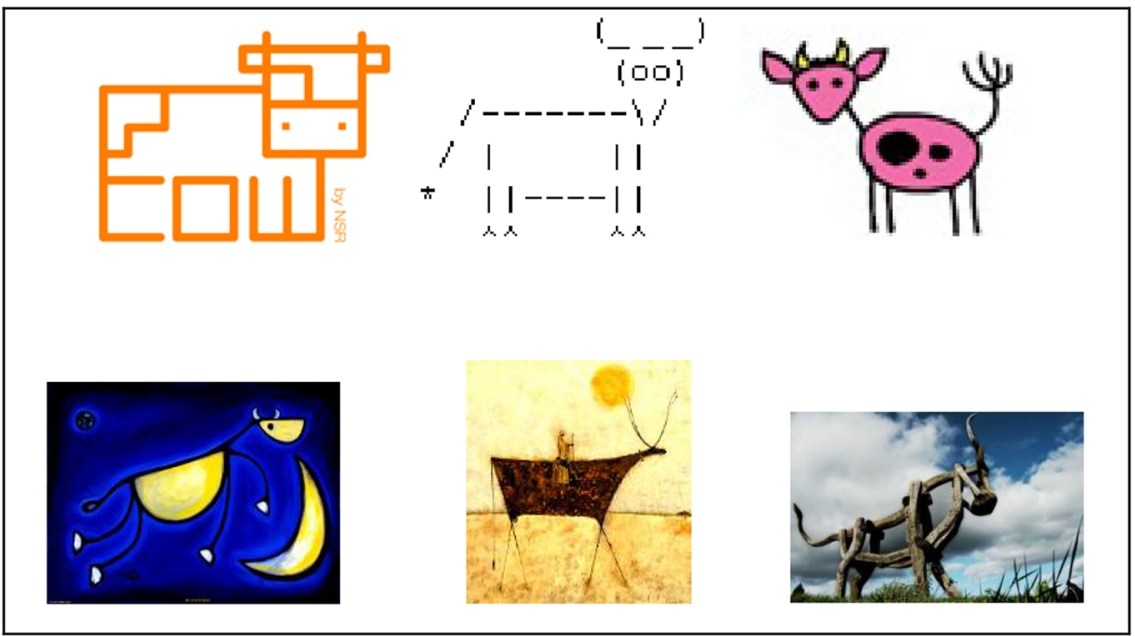

Figure 18. Simplification while preserving structural relationships can create a unique visual style.

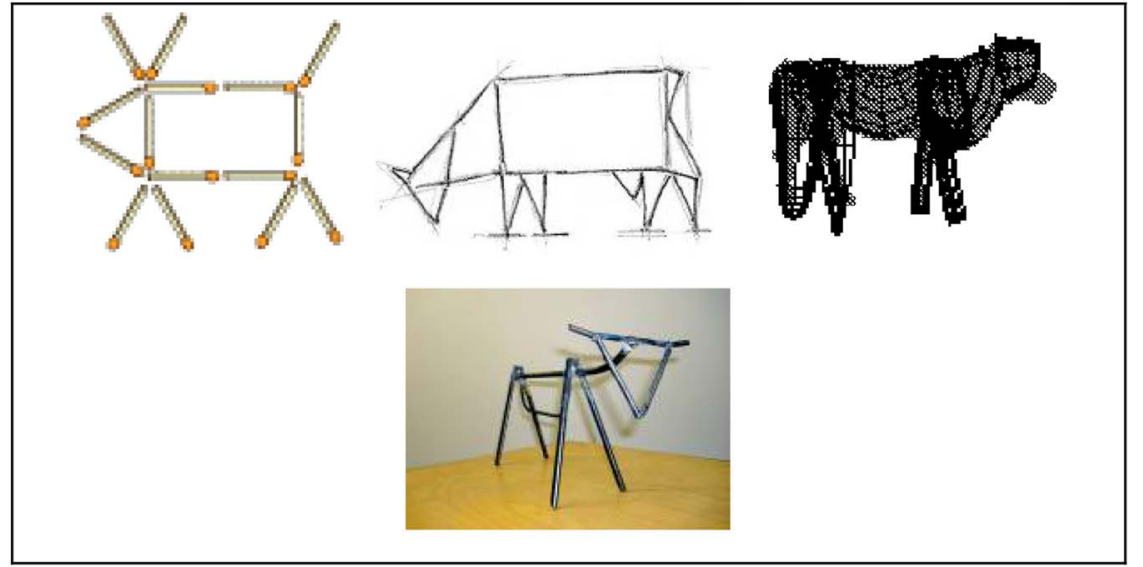

Figure 19. Simplified graphics that are difficult to recognize.
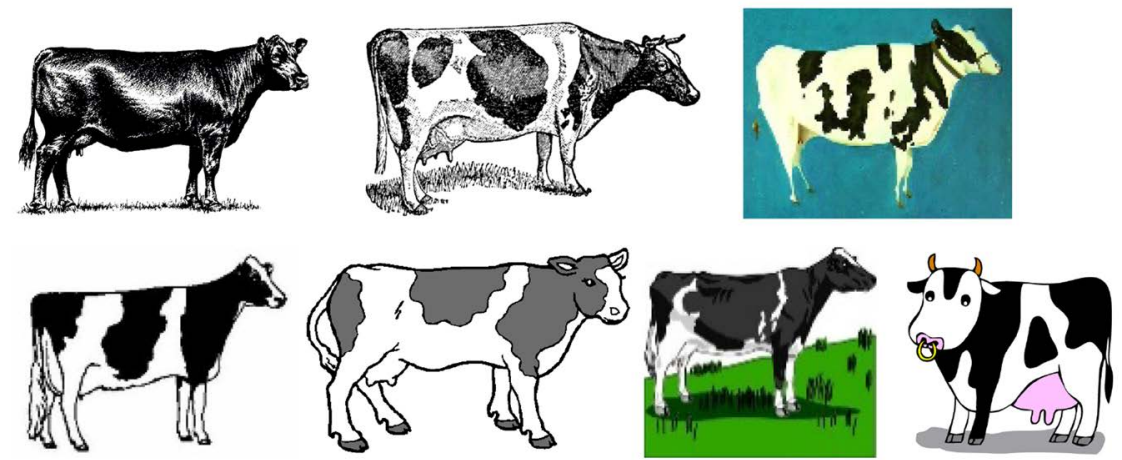

Figure 20. Simplification by flattening. 
shadows or tints can make graphics adequately identifiable depends on the designer's experience and aesthetic sense.

\section{4) Method four: Simplifying the geometry}

Simplifying the geometry of an image produces an effect similar to flattening, but does not only omit three-dimensionality. Instead, it focuses on simplifying organic shapes into straight lines and geometric curves, making them look neat and succinct, as if created with drawing tools (Figure 21).

\subsubsection{Extraction of Partial Features}

\section{1) Method one: Emphasizing visual features}

It is not always necessary to present the whole form of the subject. When extracting the partial feature, it is actually more important to present unique visual features that will enable people to identify the object it represents. Many studies have pointed out that unnecessary details may interfere with identification. This method of preserving visual features selects and emphasizes only the parts viewers are most familiar with (Figure 22 and Figure 23). However, if the subject does not have any distinctive features, or the designer has not chosen a suitably distinctive feature to be highlighted, the method may be rendered ineffective. An example is shown in Figure 24, where the defining features of the cow have not been adequately highlighted, allowing it to be mistaken for other animals.

Another advantage of using exaggerated or distorted methods to reinforce the features that make subjects unique, is that it can increase the enjoyment of simplified graphics (Figure 25).

\section{2) Method two: Emphasizing functional features}

Emphasizing functional features is similar to emphasizing visual features, which extracts the most important features of a subject. However, in addition, functional features emphasize the uniqueness of the subject carrying out a "function", rather than solely a visual element. The selection of the subject's major functional feature should follow common sense. Udders are closely associated with cows, as opposed to dogs or goats. As a result, the majority of people will associate graphics illustrating full udders with cows (Figure 26). This exaggerated method of presentation, often seen in cartoons and comic books, often makes the graphics more interesting, with a stronger impact (Figure 27).

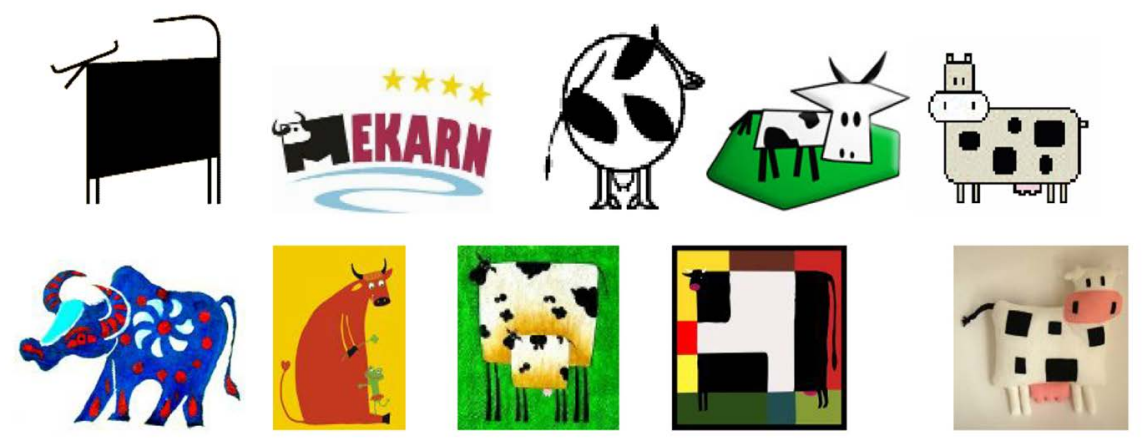

Figure 21. Simplifying the geometry. 


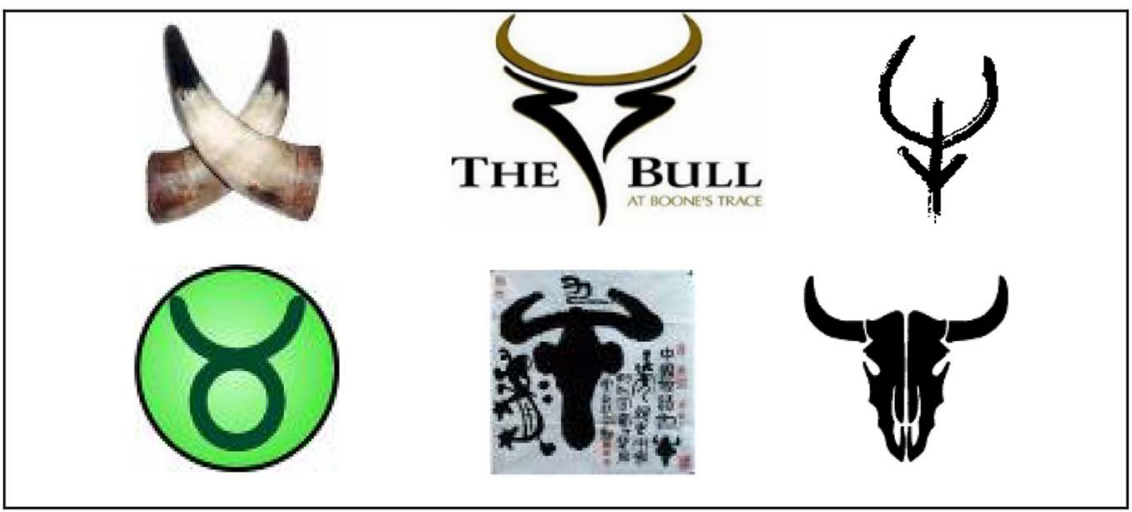

Figure 22. Reinforcement of a characteristic part of the cow, its horns.
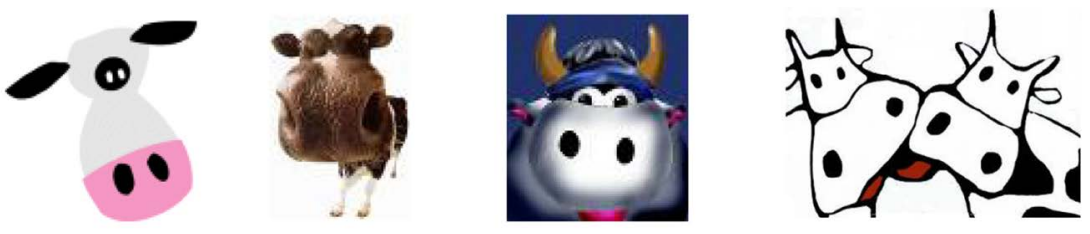

Figure 23. Reinforcement of a characteristic part of the cow, its nose.
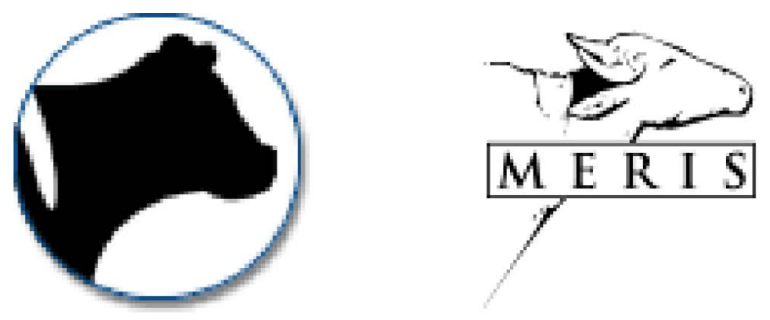

Figure 24. Major characteristic parts of the cow are not evident.
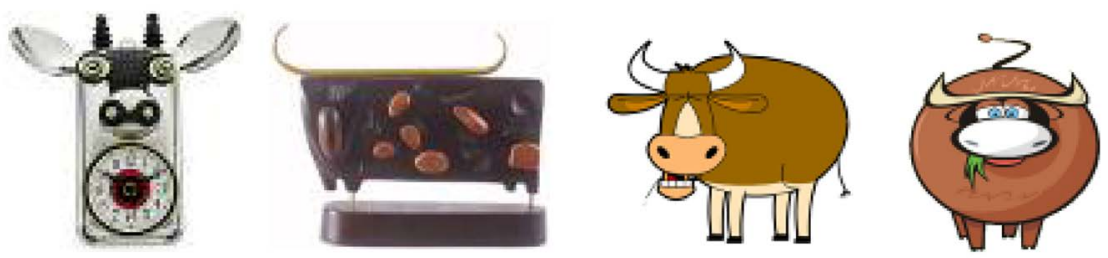

Figure 25. Exaggeration or distortion can enhance the enjoyment of simplified graphics.

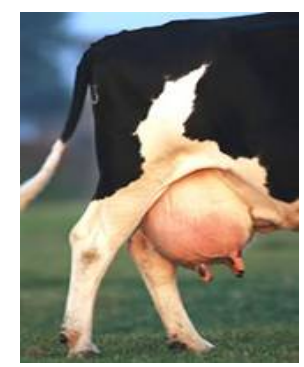

Figure 26. The functional feature of an udder may substitute for the whole cow. 


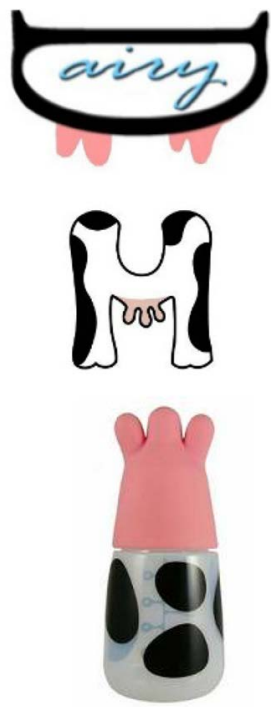

Figure 27. Graphics of a cow with exaggerated udders.

However, the methods may be used simultaneously, for example, cow's udders can belong to visual feature as well as functional feature.

\section{3) Method three: Preserving surface patterns}

The surface pattern method omits the concrete form of the subject, selecting only unique exterior patterns and shapes. Patterns on the subject must be easily identifiable, for example: the leopard's spots, the tiger's irregular stripes, the zebra's black and white stripes. Even without its form, a credible and convincing image of a subject can be presented if the surface is patterned (Figure 28). Moreover, patterns may enhance the vividness and richness of visuals.
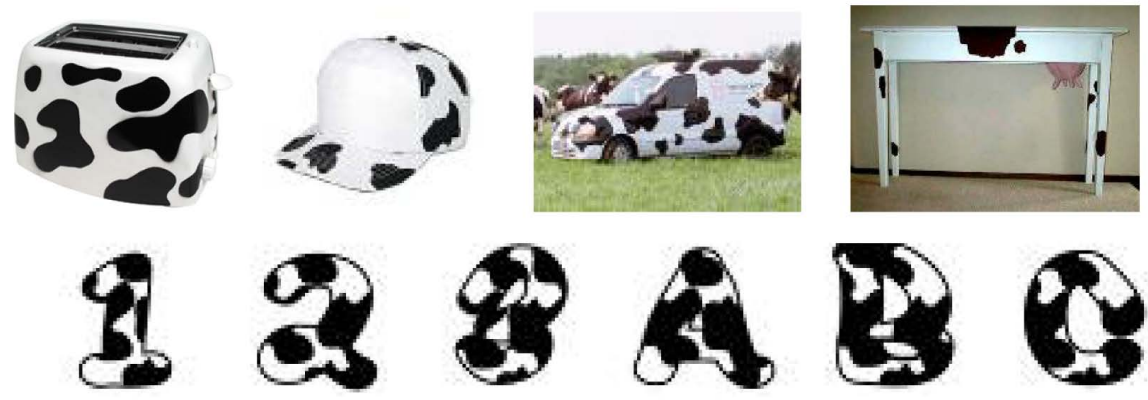

Figure 28. Pattern simplification and preservation of material characteristic of the cow.

\section{Conclusion and Suggestion}

Analysis of design methods helps in understanding of each method's features. Classification allows designers to understand the consequences of using each method in dealing with different design aspects and problems. Therefore, classification and explanation of the simplification method provide a helpful reference for practical design and design teaching. This study used literature review and the focus group technique to explore the categories and features of design simplification. The conclusion revealed that graphic simplification may primarily be 
divided into two modes, extraction of the complete form and extraction of partial features. The extraction of the complete form may be further divided into: rendering external outlines, preserving structural relationships, flattening and simplifying the geometry. The extraction of partial features may in turn be divided into: emphasizing visual features, emphasizing functional features, and preserving surface patterns.

The present research focused on graphic simplification methods on turning an original object into a two-dimension representation, and the other fields, such as typography, package design, or painting artworks that were not discussed in this article, are worth to be explored in the future study.

It is hoped that the explanation and analysis of these methods in this study will provide a helpful reference for design teaching and practical design. Better understanding of the Principle of Simplicity, and knowledge of the features of each method, will aid inexperienced designers in creating effective graphics. Moreover, this study recommends that future research from the perspective of computer-aided design to be conducted in greater depth. For instance, "Quick. Draw" (Jongejan, 2016), built by Google Creative Lab and Data Arts Team, is a game that you draw, and a neural network tries to guess what you're drawing. However, it doesn't always work. For the cow on the left of Figure 29, the

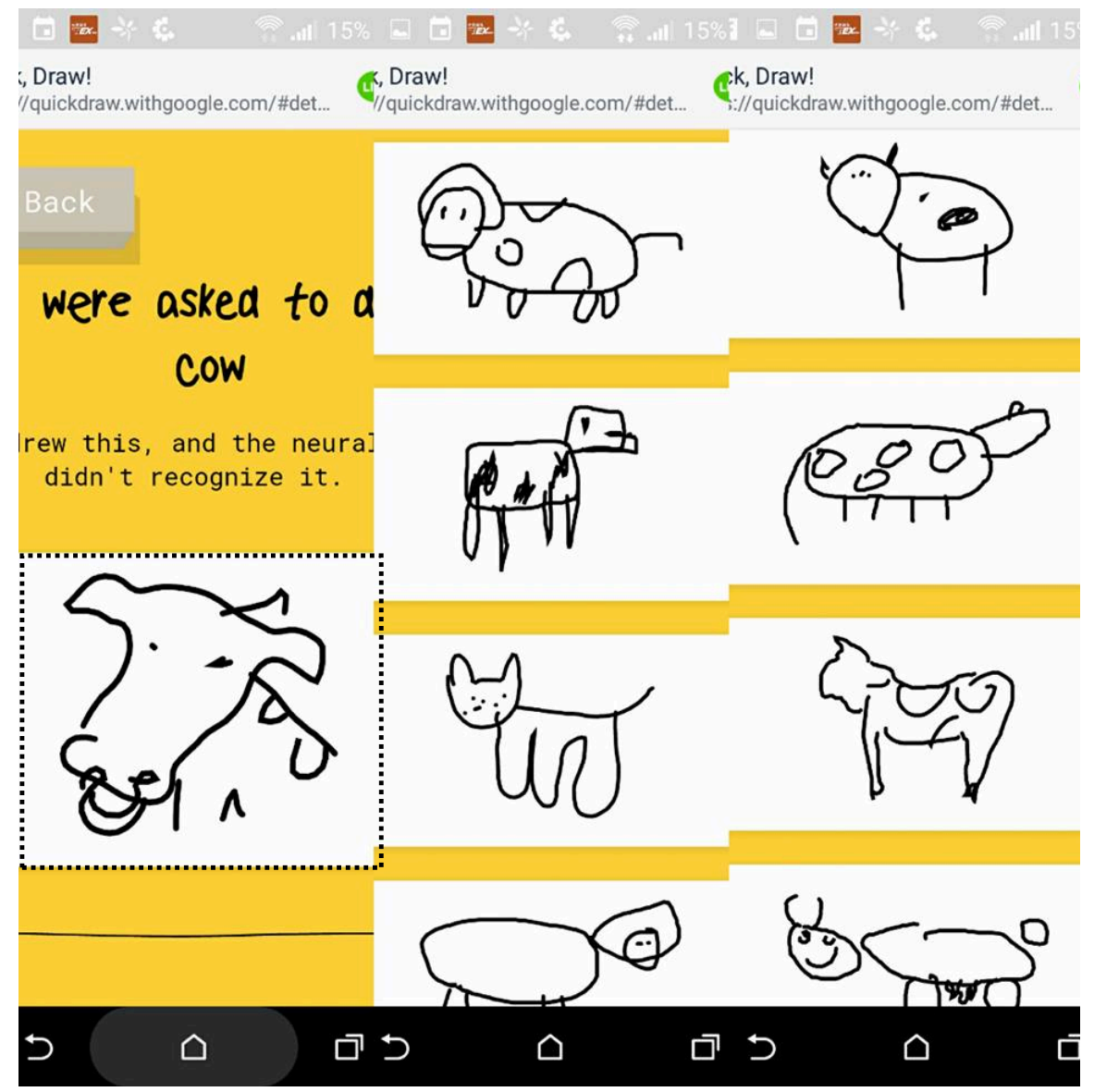

Figure 29. "Quick.Draw” (from https://quickdraw.withgoogle.com/). 
system can't recognize the partial feature as a cow while can recognize other cows that preserve the complete structure on the right side. Results of the present research may provide the game team a useful reference on how people draw and recognize the cow.

\section{Note}

Rosch, Mervis, Gray, Johnson, \& Boyes-Braem (1976) proposed that basic-level objects appeared to be the most abstract categories for which an image could be reasonably representative of the class as a whole.

\section{References}

Arnheim, R. (1969). Visual Thinking. Berkeley: University of California Press.

Arnheim, R. (1974). Art and Visual Perception: A Psychology of the Creative Eye. Berkeley: University of California Press.

Aynsley, J. (2001). A Century of Graphic Design. New York: Hauppauge.

Bell, C. (1913). Art. London: Chatto and Windus.

Eysenck, M., \& Keane, M. (2005). Cognitive Psychology-A Student's Handbook. Cambridge: Psychology Press.

Eysenck, M. (Ed.) (1998). Psychology: An Integrated Approach. England: Prentice-Hall.

Goldstein, B. (2002). Sensation and Perception. Belmont, CA: Wadsworth-Thomson Learning.

Gombrich, E. H. (1982). The Image \& the Eye. London: Phaidon Press Ltd.

Hsiung Shih Arts (Ed.) (1976). Picasso. Picasso. Taipei: Hsiung Shih Arts.

Hsu, C. C., \& Wang, R. (2005). Redefining Abstraction in Visual Art and Design. Journal of Design, 10, 81-99.

Hsu, C. C., \& Wang, R. (2010). The Relationship between Shape Features and Degrees of Graphic Simplification. Journal of Design, 15, 87-105.

Jongejan, J. (2016). Quick, Draw! https://quickdraw.withgoogle.com/

Koffka, K. (1935). Principles of Gestalt Psychology. London: Lund Humphries.

Kress, G., \& Van Leeuwen, T. (1996). Reading Images: The Grammar of Visual Design. London: Routledge.

Krueger, R. A., \& Casey, M. A. (2000). Focus Group: A Practical Guide for Applied Research (3rd ed.). Thousand Oaks, CA: Sage. https://doi.org/10.1037/10518-189

Lin, R. (1992). An Application of the Semantic Differential to Icon Design. Proceedings of the Human Factors Society 36th Annual Meeting, Atlanta, GA, 12-16 October 1992. https://doi.org/10.1177/154193129203600416

Lin, R. (1994). A Study of Visual Features for Icon Design. Design Studies, 15, 185-197. https://doi.org/10.1016/0142-694X(94)90024-8

Lippard, L. R. (1985). Pop Art. New York: Thames and Hudson.

Meggs, P. (1997). Six Chapters in Design: Saul Bass, Ivan Chermayeff, Milton Glaser, Paul Rand, Ikko Tanaka, Henryk Tomaszewski. San Francisco, CA: Chronicle Books.

Meyer, P., \& Laveson, I. (1981). An Experience Judgement Approach to Tactical Flight Trainning. Proceedings of the Human Factors Society-25th Annual Meeting, Rochester, NY, 12-16 October 1981. 
Palmer, S., Rosch, E., and Chase, P. (1981). Canonical Perspective and the Perception of Objects. In J. Long, \& A. Baddeley (Eds.), International Symposium on Attention and Performance (Attention and performance IX) (pp. 135-151). Hillsdale, NJ: Lawrence Erlbaum Associates.

Read, H. E. (1985). A Concise History of Modern Painting. New York: Thames and Hudson.

Rosch, E., Mervis, C. B., Gray, W. D., Johnson, D. M., \& Boyes-Braem, P. (1976). Basic Objects in Natural Categories. Cognitive Psychology, 8, 382-439. https://doi.org/10.1016/0010-0285(76)90013-X

Wang, R., \& Hsu, C. C. (2007). Study of the Design Operation of Graphic Simplification. The Design Journal, 10, 54-73. https://doi.org/10.2752/146069207789271894 